\title{
Double-ligand strategy to construct inhibitor-loaded Zn-MOF and its corrosion protection ability for aluminum alloy $2 \mathrm{A12}$
}

You Zhang, ${ }^{* a, b}$ Juping Wang, ${ }^{a}$ Shuai Zhao, ${ }^{\text {a }}$ Maria Serdechnova, ${ }^{\mathrm{b}}$ Carsten Blawert, ${ }^{\mathrm{b}}$ Hao Wang, ${ }^{* a}$ Mikhail L. Zheludkevich, ${ }^{\text {b,c }}$ and Fei Chen ${ }^{\text {a }}$

a College of New Materials and Chemical Engineering, Beijing Key Lab of Special Elastomeric Composite Materials, Beijing Institute of Petrochemical Technology, Beijing 102617, China

b Institute of Surface Science, Helmholtz-Zentrum Hereon, Geesthacht 21502, Germany

c Faculty of Engineering, Kiel University, Kiel 24143, Germany

* Corresponding author. E-mail address: youzhang@bipt.edu.cn (Y. Zhang); wanghao@bipt.edu.cn (H. Wang). 


\section{Characterization of the Zn-MOF}

Thermal stability study for Zn-MOF was performed using TG/DTG analyzer STA 449C (NETZSCH, Germany), ranging from $0{ }^{\circ} \mathrm{C}$ to $800{ }^{\circ} \mathrm{C}$ at a heating rate of $10{ }^{\circ} \mathrm{C} / \mathrm{min} . \mathrm{N}_{2}$ adsorption-desorption isotherms were measured to understand the structures, which performed at $77 \mathrm{~K}$ using a BELSORP-mini apparatus (BEL, Japan).

\section{Preparation of Zn-BTA powder}

A mixture of $\mathrm{Zn}\left(\mathrm{NO}_{3}\right)_{2} \cdot 6 \mathrm{H}_{2} \mathrm{O}(0.3 \mathrm{~g}, 1.0 \mathrm{mmol}), \mathrm{Na}_{2} \mathrm{CO}_{3}(0.10 \mathrm{~g}, 1.0 \mathrm{mmol})$, benzotriazole $(0.24 \mathrm{~g}, 2.0 \mathrm{mmol})$ in molar ratio $1: 1: 2$ and $10 \mathrm{ml} \mathrm{H}_{2} \mathrm{O}$ was placed in a Parr Teflon-lined stainless steel vessel $\left(25 \mathrm{~cm}^{3}\right)$, then the vessel was sealed and heated to $160{ }^{\circ} \mathrm{C}$. The temperature was hold for 3 days, then the reactant mixture was cooled at a rate of $0.5{ }^{\circ} \mathrm{C} / \mathrm{min}$ to lead to the formations of colorless crystals of $\mathrm{Zn}$-BTA $\left(\mathrm{C}_{12} \mathrm{H}_{8} \mathrm{~N}_{6} \mathrm{Zn}\right){ }^{1}$ 

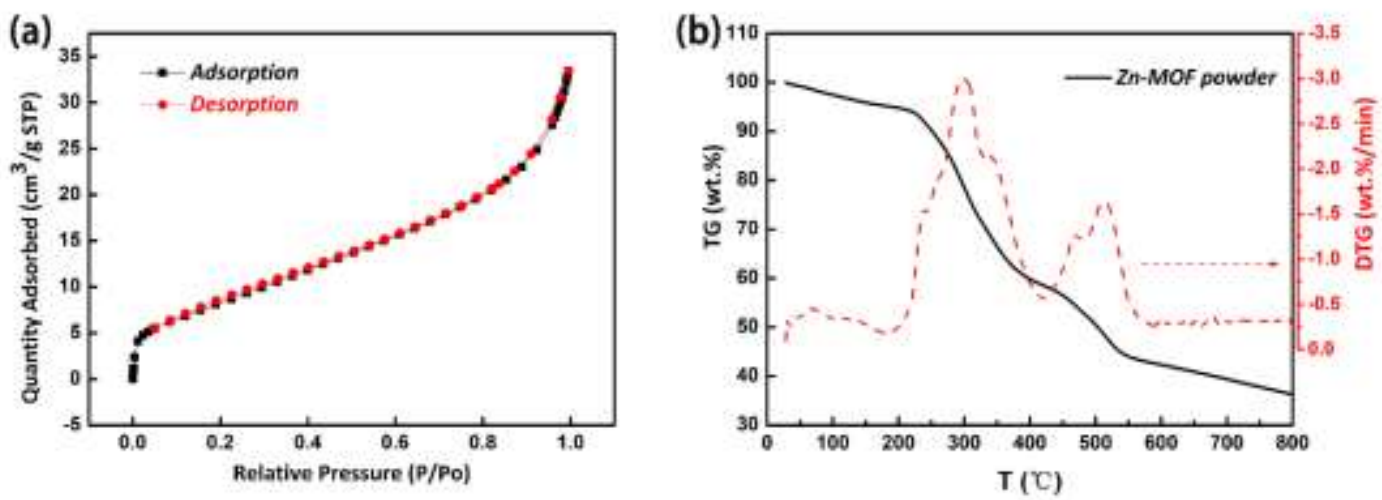

Figure S1 (a) BET analysis and (b) TG/DTG analysis of the Zn-MOF powder.

Figure S1a depicts characteristics type I isotherm and microporous materials with adsorption stripping curves..$^{2-7}$ The adsorption capacity increases to a certain extent rapidly when the relative pressure is low and vice versa. There is an obvious tiny-lag ring in the relative pressure of $0.8 \sim 0.9$, indicating existence of small pores. ${ }^{8}$ The BET surface area of Zn-MOF was estimated to be $31.128 \mathrm{~m}^{2} / \mathrm{g}$ with a pore size of size distribution of $1.042 \mathrm{~nm}$ and a small pore volume of $0.049 \mathrm{~cm}^{3} / \mathrm{g}$.

TG/DTG curves of Zn-MOF are shown in Figure S1b. The first mass loss of $\mathrm{Zn}-\mathrm{MOF}$ is $10 \%$ in the temperature range of $28-250{ }^{\circ} \mathrm{C}$, which could be ascribed to the evaporation of solvents molecules (the methanol) from the Zn-MOF. Subsequently, the weight loss slightly decreased to $40 \mathrm{wt} . \%$ when the temperature was increased to $358{ }^{\circ} \mathrm{C}$, indicating the decomposition of Zn-MOF. The third minority loss occurred after $450{ }^{\circ} \mathrm{C}$, which was attributed to the decomposition of the remaining composition of Zn-MOF. 

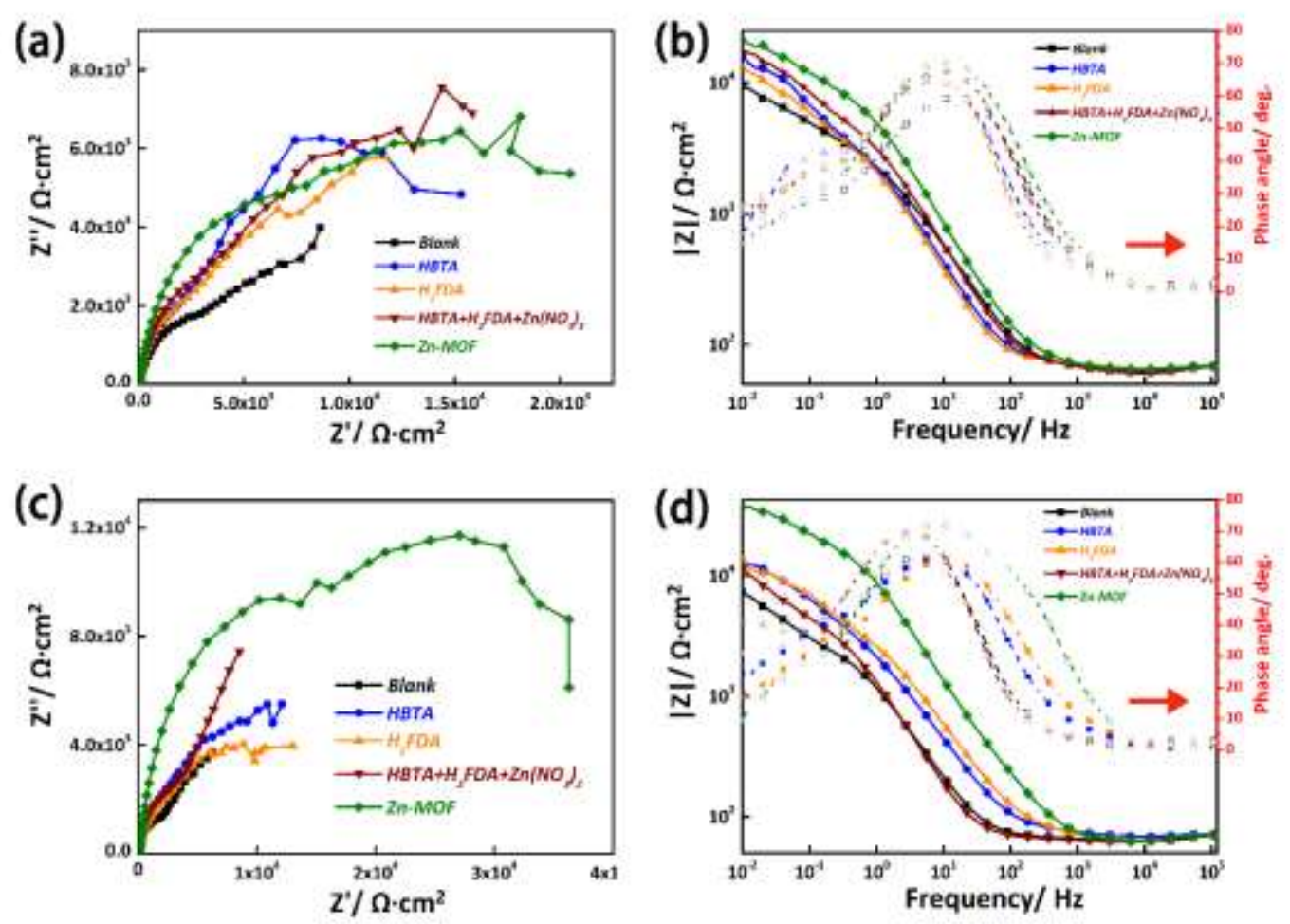

Figure S2 (a) Nyquist and (b) Bode plots of Al alloy plates after 2 days of immersion;

(c) Nyquist and (b) Bode plots of Al alloy plates after 7 days of immersion in $0.05 \mathrm{M}$

$\mathrm{NaCl}$ solution standalone and with additions of HBTA, $\mathrm{H}_{2}$ FDA, HBTA\&

$\mathrm{H}_{2} \mathrm{FDA} \& \mathrm{Zn}^{2+}$ mixture or $\mathrm{Zn}-\mathrm{MOF}$. 
References:

(1)Hu, R. F.; Jian, Z.; Kang, Y. A fluorescent Znbenzotriazole 2D polymer with $(6,3)$ topology. Inorganic Chemistry Communications. 2005, 8(9), 828-830.

(2)Batrakova, M. K.; Solovtsova, O. V.; Fomkin, A. A. Synthesis and StructureEnergy Characteristics of an MOF Al-BTC Organometallic Framework Structure. Protection of Metals and Physical Chemistry of Surfaces. 2017, 53, 961-966.

(3)Guo, H.; Mei, W.; Liu, J. Facile synthesis of nanoscale high porosity IR-MOFs for low-k dielectrics thin films. Microporous and Mesoporous Materials. 2016, 221, 40-47.

(4)Kim, H.; Kim, H.; Kim, K. Structural Control of Metal-Organic Framework Bearing N-Heterocyclic Imidazolium Cation and Generation of Highly Stable Porous Structure. Inorganic Chemistry. 2019, 58(10), 6619-6627.

(5)Zhang, X.; Li, D.; Dong, C. The synergistic supercapacitive performance of Mo-MOF/PANI and its electrochemical impedance spectroscopy investigation. Materials Today Communications, 2019, 21, 100-711.

(6)Minmini, R.; Naha, S.; Velmathi, S. New Zinc functionalized metal organic Framework for selective sensing of chromate ion. Sensors and Actuators B Chemical. 2017, 251, 644-649.

(7)Abid, H. R.; Pham, G. H.; Ang, H. M. Adsorption of $\mathrm{CH}_{4}$ and $\mathrm{CO}_{2}$ on $\mathrm{Zr}$-metal organic frameworks. Journal of Colloid \& Interface Science, 2012, 366(1), 120-124. 
(8)Zhan, M.; Hussain, S.; Algarni, T. S. Facet Controlled Polyhedral ZIF-8 MOF Nanostructures for Excellent NO2 Gas-Sensing Applications. Materials Research Bulletin, 2020, 136(41), 111-133. 